\title{
Solubility of gases in liquids: a critical review
}

\author{
Emmerich Withelm \\ Institut für Physikalische Chemie, Universität Wien, Währingerstraße 42 , \\ A-1090 Wien, Austria
}

\begin{abstract}
Selected theoretical and experimental aspects of vapor-liquid equilibria involving supercritical (noncondensable) components are reviewed. The focus is on the rigorous thermodynamic basis on which high-precision methods for the determination of Henry coefficients have to rest. A condensed outline of current theories and correlations for the prediction of auxiliary quantities, such as virial coefficients and partial molar volumes, is presented. Finally, attention is given to recent work on relatively simple aqueous solutions of nonelectrolytes, which may contribute towards a better understanding of hydrophobic effects.
\end{abstract}

\section{INTRODUCTION}

The years since 1970 have been marked by intense activity in the field of solutions of nonelectrolytes in general, and of the solubility of gases in liquids in particular. The wealth of new and precise experimental data (often a consequence of novel designs of apparatus), the development of refined solution theories, and the recognition of the central role in science of effective communication and dissemination of data, are documented representatively by Refs.(1-32). This activity can be traced to requirements originating in rather diverse areas of the pure and applied sciences. For instance, chemical process design often needs reliable estimates of vapor-liquid equilibria (VLE) for mixtures containing one or more components at rather low concentrations (trace components), which are either supercritical (noncondensable) or only slightly subcritical. Other areas, where gas solubility data are frequently needed, are geochemistry, environmental science (pollution control) and biomedical technology. Since life cannot exist without water, studies of simple aqueous solutions, in particular of the rare gases and of hydrocarbons, have held a prominent position in biophysics. Perhaps most important, studies on such model systems have provided information on hydrophobic effects, which are thought to be of importance in complex biological processes. By way of example we 1 ist a few application-oriented topics of recent interest: strongly enhanced solubility of oxygen in perfluorinated hydrocarbons (33) as compared to the solubility in the parent hydrocarbons - these substances are chemically inert enough to be used as blood substitutes and as gas carriers in 1iquid breathing (34,35); solubility of gases in long-chain alcohols (36) and its relation to anesthetic potency (37, 38); solubility of Freons in water (39), and of oxygen and ozone in water (waste water treatment) $(40,41)$; removal of $\mathrm{CO}_{2}$ and $\mathrm{H}_{2} \mathrm{~S}$ from sour natural or synthetic gases by mixedsolvent absorption (gas sweetening) (42-44); solubility of hydrogen and other light gases in high molecular weight solvents $(45,46)$, which is of importance for a number of engineering processes such as hydrofining of $0 i 1$ and coal, and enhanced oil recovery; solubility of gases in aqueous solutions of surfactants (solubilization) (47). 
such a vast literature, as evidenced by the various representative reviews, state-of-the-art reports and data compilations cited above. Because of this diversity, a certain variation of experimental as well as theoretical methods used in each of these areas is almost inevitable, and makes it impossible to cover all of them in one short review. Far from being exhaustive, this article will therefore focus on just a few selected areas with the bias reflecting current research interests of the author. First, a rigorous discussion of the thermodynamic fundamentals relevant to the solubility of gases in 1 iquids will be presented. This will be followed by an appraisal of recent experimental developments and of advances pertinent to data reduction and correlation. A condensed outline of current methods for the prediction of important auxiliary quantities, such as virial coefficients and partial molar volumes, will be included. The last section will be devoted almost entirely to recent work on relatively simple aqueous solutions of nonelectrolytes (with special attention to hydrophobic effects).

In a loose way, the expression "solution of gas(es) in liquid(s)" is usually meant to characterize VLE in multicomponent mixtures where one or more of the components are supercritical or only slightly subcritical at the experimental temperature, and where the 1iquidphase mole fraction $x_{2}$ of the "gas" is much smaller than that of the solvent. At room temperature and at a partial pressure of "gas" of about $100 \mathrm{kPa}$, mole fraction solubility values for gases like Ar, $\mathrm{N}_{2}$ or $\mathrm{CH}_{4}$ dissolved in 1 iquids such as benzene, methanol or water are roughly between $10^{-4}$ and $10^{-2}$. Clearly, some arbitrariness is involved and such a classification is to be taken as a mere heuristic convenience to deal with corresponding VLE data, i.e. with "gas-solubility data". Most of what follows will concern the solubility of a pure gas in a pure liquid. Gas solubilities in mixed solvents, though undoubtediy of considerable practical as well as theoretical interest, will only be touched upon. Further, problems associated with solutions of chemically reacting gases will not be treated to any extent. Those with a specific interest in these topics are referred to Refs. $(1,20,23,48-53)$.

\section{THERMODYNAMICS}

When discussing equilibria of phases containing more than one component, it is frequently convenient to distinguish between a mixture or a solution, and a dilute solution. In a mixture al1 components are on equal footing; thermodynamically they are all treated in the same manner, that is to say symmetrically. On the other hand in a dilute solution, one (or several) of the components is/are present in great excess and form(s) the solvent or mixed solvent, while the remaining component(s) at usually rather low mole fraction(s) is/are classified as solute(s). In general, the thermodynamic treatment of dilute solutions focuses on the solute(s), that is to say it will be asymmetric. These statements will be quantified below. There is nothing fundamental in this distinction between a dilute solution and a mixture, and although not always stated explicitly, thermodynamic analysis of gas-solvent systems proceeds essentially along the lines as for other phase equilibrium problems. It seems thus permissible to present here only a rather condensed treatment and to refer for details to the appropriate reviews $(22,31)$ and monographs $(1,20,24)$, in particular to the excellent recent book by Van Ness and Abbott (24), which contains a section on the reduction and correlation of gas-solubility data. 
each phase. The fundamental relations characterizing phase equilibrium between two phases are those which equate the chemical potential of each component $i=1, \ldots, K$ in one phase to its chemical potential in the other. This equilibrium condition may be replaced advantageously by the rigorously equivalent criterion of equality of the component fugacities $f_{i}$. For VLE this can be expressed in compact notation as

$$
f_{i}^{V}\left(T, P,\left\{x^{V}\right\}\right)=f_{i}^{L}\left(T, P,\left\{x^{L}\right\}\right), \quad i=1, \ldots, K,
$$

where the superscripts $V$ and $L$ indicate the vapor phase and the 1 iquid phase, respectively, $\left\{x^{V}\right\}$ denotes the set of $(K-1)$ independent vapor-phase mole fractions $\left\{x_{1}, \ldots, x_{K-1}^{V}\right\}$, and $\left\{x^{L}\right\}$ denotes the set of $(K-1)$ independent liquid-phase mole fractions. As indicated in Eq. ( $\left.\uparrow\right)$ the fugacities depend on temperature, pressure and composition. Two methods are commoniy used to establish the link with experimental practice. In the first, the equilibrium condition is rewritten in terms of the fugacity coefficients

$$
\phi_{i}(T, P,\{x\}) \equiv f_{i} /\left(x_{i} P\right)
$$

in both phases $L$ and $V$. In the second method the fugacities in the vapor phase are again expressed in terms of $\phi_{j}$, while the liquid-phase fugacities are expressed in terms of liquid-phase activity coefficients

$$
\gamma_{i}^{L}\left(T, P,\left\{x^{L}\right\}\right) \equiv f_{i}^{L} /\left(x_{i}^{L} f_{i}^{0 L}\right),
$$

where $f_{i}^{\circ}$ is an appropriate standard-state fugacity. Setting $\{y\} \equiv\left\{x^{V}\right\}$ and dropping the superscript $L$ where permissible, Eq.(1) may be recast in the following two entirely equivalent ways:

$$
\begin{array}{ll}
y_{i} \phi_{i}^{V}(T, P,\{y\})=x_{i} \phi_{i}^{L}(T, P,\{x\}) & i=1, \ldots, k, \\
y_{i} \phi_{i}^{V}(T, P,\{y\}) P=x_{i} \gamma_{i}(T, P,\{x\}) f_{i}^{0}(T, P) & i=1, \ldots, k .
\end{array}
$$

Each equation may serve as a rigorous basis for the treatment of VLE problems. Note that both Eqs.(4) and (5) in fact represent $K$ highly complex equations relating $2 K$ variables $(T, P,\{x\},\{y\})$. Hence - in accord with the phase rule - $K$ variables have to be specified to allow solution for the remaining $K$ unknowns. The decision as to what approach should be preferred is by and large a matter of convenience and of taste. For high pressure VLE involving fairly simple substances, the use of a single equation of state (EOS) valid for both phases has often computational advantages and a certain aesthetic appeal, and thus Eq.(4) may be selected. Eq.(5) is the one most frequently used in the thermodynamic analysis of VLE (data reduction or VLE calculations) at low to moderate pressures. In this case, an EOS is required only for the low-density vapor phase (often the virial EOS is useful), while for the liquid phase usually an adequate activity coefficient model (or more precisely an analytical expression for the excess molar Gibbs energy $G^{E}$ as a function of the $x_{i}$ ) is introduced; see however also Refs. $(54,55)$ for numerical methods. Since the emphasis of this review is on gas solubilities at rather low pressures and temperatures well below the critical temperature $\mathrm{T}_{\mathrm{c}, 1}$ of the solvent (see Note a), only the $(\gamma, \phi)$-method, Eq. (5), will be considered; the

Note a: Throughout this article, a subscript $c$ will denote a "critical quantity", and reduced quantities $Q_{r} \equiv Q / Q_{c}$ will be designated by a subscript $r$. A subscript $s$ indicates "orthobaric (i.e. saturation) conditions". Superscripts • identify either "standard-state quantities" or "perfect-gas-state quantities", * is reserved for "pure-substance quantities", and $\infty$ indicates "infinite dilution". 
$(\phi, \phi)$-method will not be pursued further. In what follows now on binary systems, component 1 will always be the subcritical solvent and component 2 will be the dissolved gas (usually, but not necessarily a supercritical fluid).

So far nothing has been decided as to the choice of standard states, which is in fact again largely a matter of convenience. Two conventions are in common use. One is based on ideal behavior in the sense of the Lewis-Randall rule, that is to say for all components we identify $f_{i}^{\circ}$ with $f_{i}^{*}$, the fugacity of the pure component $i$ in either a real or hypothetical 1 iquid state at $(T, P)$ of the solution. Thus, reality is compared with the behavior of the model fluid "ideal solution (Lewis-Randa11)", where

$$
f_{i}^{\text {id }}=x_{i} f_{i}^{*}(T, P), \quad i=1 \text { or } 2 \text {. }
$$

The other convention distinguishes between the solvent and the solute and is based on ideal behavior of the latter in the sense of Henry's law, that is to say for component 1 (solvent) $f_{1}^{\circ}=f_{1}^{*}$, whereas for component 2 (solute) $f_{2}^{\circ}$ is identified with the Henry coefficient $H_{2,1}$, all at $(T, P)$ of the solution. Thus, reality is compared with the behavior of the model fluid "idea1-dilute solution (Henry)", where

$$
\left.\begin{array}{l}
f_{1}^{i d}=x_{1} f_{1}^{*}(T, P) \\
f_{2}^{i d}=x_{2} H_{2,1}(T, P)
\end{array}\right\}
$$

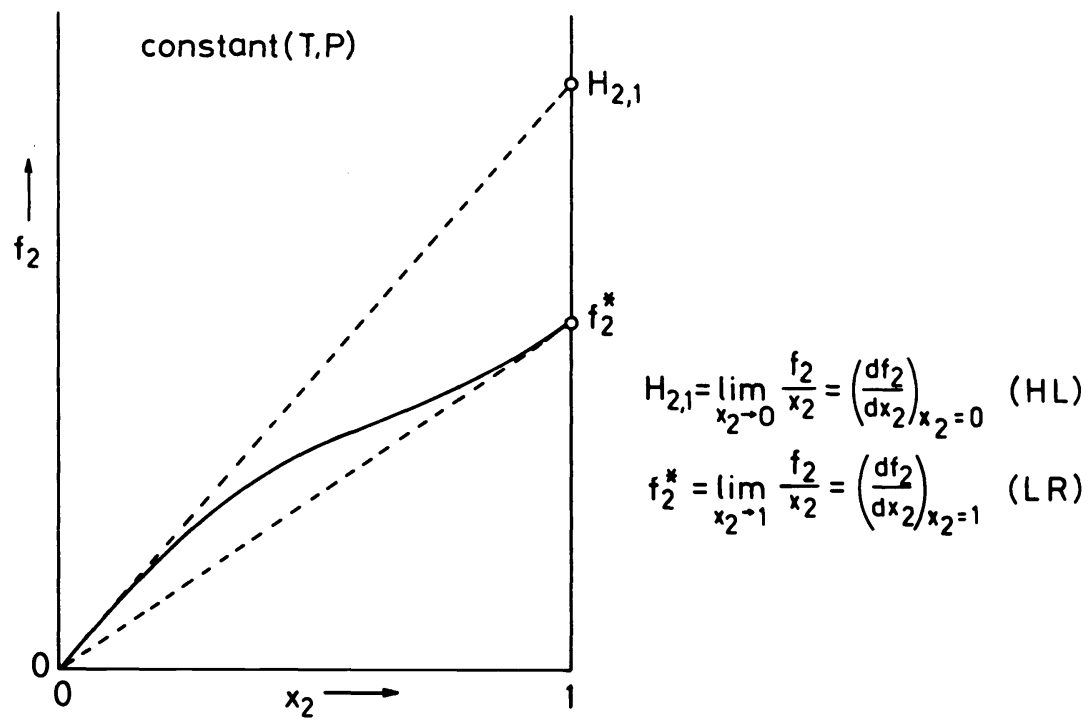

Fig. 1. Composition dependence of component fugacity $f_{2}$ in a binary solution at constant $(T, P) . f_{2}^{*}$ is the fugacity of pure substance 2 and $\mathrm{H}_{2,1}$ is the Henry coefficient. The dashed 1 ines represent Henry's law (HL) and the Lewis-Randal1 rule (LR), respectively. 
Corresponding to these two conventions, the liquid-phase activity coefficients are normal ized either symmetrically

$$
\left.\begin{array}{lll}
\gamma_{1}-1 & \text { as } & x_{1}-1 \\
\gamma_{2}-1 & \text { as } & x_{2}-1
\end{array}\right\}
$$

or unsymmetrically

$$
\left.\begin{array}{c}
\gamma_{1}-1 \text { as } \quad x_{1} \rightarrow 1 \\
\gamma_{2}^{\prime}-1 \text { as } \quad x_{2}-0
\end{array}\right\}
$$

The prime in Eq.(9) is to serve as a reminder that the unsymmetric convention of normalization has been used, that is to say $\gamma_{1}=f_{1} /\left(x_{1} f_{1}^{*}\right)$ and $\gamma_{2}^{\prime}=f_{2} /\left(x_{2} H_{2}, 1\right)$. We reiterate that the numerical value of the activity coefficient depends on the selected standard state and has no significance whatsoever unless the value of $f_{i}^{\circ}$ is specified concomitantly. The two choices of convention for the standard states are shown in Fig. 1 . Note that for a supercritical component 2 no experimental value for the liquid-state fugacity of pure 2 exists, and that $f_{2}$ is known from experiment only for $x_{2}<1$.

The symmetric convention is the most natural one for mixtures where all $T_{c, i}>T$, and where the interest is on the composition dependence of the various thermodynamic quantities in the whole range $0 \leqslant x \leqslant 1$. When $T_{c, 2}<T$ and/or when the interest is on the thermodynamics of component 2 in the dilute region, the unsymmetric convention is usually selected. It has the advantage that the Henry coefficient and hence $\gamma_{2}^{\prime}$ are unambiguously defined according to an experimental procedure (as indicated in Fig. 1); these quantities may be obtained, at least in principle, to any desired degree of accuracy. However, as an alternative in the case $T_{c, 2}<T$ one may obtain the fugacity of pure solute in a hypothetical liquid state through essentially arbitrary extrapolation of the function

$$
\ln f=x_{1} \ln \left(f_{1} / x_{1}\right)+x_{2} \ln \left(f_{2} / x_{2}\right), \quad \text { constant }(T, P)
$$

to $x_{2}=1$ : $f$ is the mixture fugacity, and $\ln \left(f_{j} / x_{i}\right)$ is the partial molar quantity associated with lnf. The resulting pure-component fugacity $f_{2}^{*}$ may then be adopted as an arbitrary standard-state fugacity for the solute and the symmetric convention may be applied. We note that for each extrapolation recipe a corresponding different set of liquid-phase activity coefficients ensues (56), each satisfying $\gamma_{2} f_{2}^{*^{L}}=f_{2}^{L} / x_{2}$.

The various quantities corresponding to these conventions are, of course, related. At constant $(T, P)$

$$
\begin{aligned}
& \ln f_{2}^{*}=\ln H_{2,1}-\ln \gamma_{2}^{\infty}, \\
& \ln \gamma_{2}=\ln \gamma_{2}^{\prime}+\ln \gamma_{2}^{\infty},
\end{aligned}
$$

where the activity coefficient at infinite dilution is given by

$$
\ln \gamma_{2}^{\infty}=\lim _{x_{2} \rightarrow 0}\left(\ln \gamma_{2}\right)=-\lim _{x_{2} \rightarrow 1}\left(\ln \gamma_{2}^{\prime}\right) \text {. }
$$

The equilibrium criteria for VLE, Eqs. $(4,5)$, provide relations at temperature $T$ and equilibrium pressure $P$ of the solution. For isothermal conditions, $P$ varies with $x_{2}$, and 
hence for each composition $\phi_{i}, \gamma_{1}$ and $\gamma_{2}^{\prime}, f_{1}^{*}$ and $H_{2,1}$ will refer to a different pressure and not to a fixed reference pressure. Thus the pressure dependence of these quantities must be known and the pertinent formulae are summarized below. For the reduction (or correlation) of gas-solubility data it is advantageous to choose the vapor pressure $P_{S, 1}$ of the solvent as the constant reference pressure. Conversion to any other reference pressure is - at least in principle - straightforward. The fugacity of the pure solvent at $(T, P)$ is related to its vapor pressure by

$$
\begin{aligned}
& f_{1}^{* L}(T, P)=f_{1}^{* L}\left(T, P_{s, 1}\right) P_{1}(T, P)=P_{s, 1} \phi_{s, 1}^{* V} P_{1}(T, P), \\
& P_{1}(T, P) \equiv \exp \left\{\int_{P_{s, 1}}^{P} \frac{V_{1}^{* L}(T, P)}{R T} d P\right\} .
\end{aligned}
$$

Here, $\phi_{S, 1}^{* V} \equiv \phi_{1}^{* V}\left(T, P_{S, 1}\right)$ is the fugacity coefficient of pure saturated solvent vapor, $V_{1}^{*}$ is the molar volume of pure liquid, and $\mathscr{P}_{1}(T, P)$ is called the Poynting correction. For the Henry coefficient we obtain

$$
\begin{aligned}
& H_{2,1}(T, P)=H_{2,1}\left(T, P_{s, 1}\right) P_{2}(T, P), \\
& P_{2}(T, P) \equiv \exp \left\{\int_{P_{s, 1}}^{P} \frac{V_{2}^{\infty L}(T, P)}{R T} d P\right\},
\end{aligned}
$$

where $V_{2}^{\infty L}$ is the partial molar volume of dissolved gas at infinite dilution. The appropriate relations for the activity coefficients are

$$
\begin{aligned}
& \gamma_{1}\left(T, P, x_{2}\right)=\gamma_{1}\left(T, P_{s, 1}, x_{2}\right) \exp \left\{\int_{P_{s, 1}}^{P} \frac{V_{1}^{L}\left(T, P, x_{2}\right)-V_{1}^{* L}(T, P)}{R T} d P\right\}, \\
& \gamma_{2}^{\prime}\left(T, P, x_{2}\right)=\gamma_{2}^{\prime}\left(T, P_{s, 1}, x_{2}\right) \exp \left\{\int_{P_{s, 1}}^{P} \frac{V_{2}^{L}\left(T, P, x_{2}\right)-V_{2}^{\infty L}(T, P)}{R T} d P\right\},
\end{aligned}
$$

where $V_{i}^{L}\left(T, P, x_{2}\right)$ is the partial molar volume of component $i(=1$ or 2$)$ at mole fraction $x_{2}$. As concerns the fugacity coefficient $\phi_{i}$ of species $i$, we present two perfectly general equations valid for $V$ as well as for $L$, which allow its determination either in terms of a pressure-explicit or a volume (density)-explicit EOS, provided of course, that the EOS are valid over the entire ranges of integration. When a pressure-explicit EOS $P / \rho R T \equiv Z=Z(T, \rho,\{x\})$ is used

$$
\ln \phi_{i}=\int_{0}^{\rho}\left[\left(\frac{\partial n Z}{\partial n_{i}}\right)_{T, \rho / n, n_{j}}-1\right] \rho^{-1} d \rho-\ln Z, \text { constant }(T,\{x\}) .
$$

Here $\rho=V^{-1}$ is the molar density of the mixture, $n_{i}$ is the amount of substance $i, n=\sum n_{i}$, and $Z$ is the compressibility factor of the mixture. The corresponding expression for a volume (density)-explicit EOS $Z=Z(T, P,\{x\})$ is 


$$
\ln \phi_{i}=\int_{0}^{P}\left(Z_{i}-1\right) P^{-1} d P, \quad \text { constant }(T,\{x\}),
$$

where $z_{i} \equiv P V_{i} / R T$ and $V_{i} \equiv\left(\partial n V / \partial n_{i}\right)_{T, P, n_{j}}$ is the partial molar volume of $i$ in the solution. Since the majority of EOS are pressure-explicit rather than volume-explicit, Eq.(20) is more useful in VLE problems than Eq.(21). The appropriate formulae for the pure-substance fugacity coefficients $\phi_{i}^{*}$ are, with obvious notation,

$$
\ln \phi_{i}^{*}=\int_{0}^{\rho_{i}^{*}}\left(Z_{i}^{*}-1\right)\left(\rho_{i}^{*}\right)^{-1} d \rho_{i}^{*}+Z_{i}^{*}-1-\ln Z_{i}^{*} \text {, constant } T
$$

and

$$
\ln \phi_{i}^{*}=\int_{0}^{P}\left(Z_{i}^{*}-1\right) P^{-1} d P, \quad \text { constant } T
$$

We now have at hand the thermodynamic formalism for a rigorous discussion of the reduction and correlation of gas-solubility data on the basis of the $(\gamma, \phi)$-approach in the unsymmetrical version $(22,24,31)$. Isothermal conditions are assumed throughout and the vapor pressure $P_{S, \uparrow}$ of pure solvent is always chosen as the reference pressure. For the solute the equilibrium criterion Eq.(5) may be replaced by

$$
y_{2} \phi_{2}^{V}\left(T, P, y_{2}\right) P=x_{2} \gamma_{2}^{\prime}\left(T, P_{s, 1}, x_{2}\right) H_{2,1}\left(T, P_{s, 1}\right) \exp \left\{\int_{P_{s, 1}}^{P} \frac{V_{2}^{L}\left(T, P, x_{2}\right)}{R T} d P\right\},
$$

where use was made of Eqs. $(16,17,19)$. Analogous1y, for the solvent we now have

$$
y_{1} \phi_{1}^{V}\left(T, P_{, y_{2}}\right) P=x_{1} \gamma_{1}\left(T, P_{s, 1}, x_{2}\right) P_{s, 1} \phi_{s, 1}^{*} \exp \left\{\int_{P_{s, 1}}^{P} \frac{V_{1}^{L}\left(T, P, x_{2}\right)}{R T} d P\right\} \text {. }
$$

Note that both $\gamma_{1}$ and $\gamma_{2}^{\prime}$ of Eqs. $(24,25)$ are constant-pressure activity coefficients which, at fixed temperature, depend only on liquid-phase composition. They are by definition independent of the system pressure. Their advantages have been discussed in detail by Prausnitz (1). In particular, they satisfy the isothermal-isobaric Gibbs-Duhem equation

$$
x_{1} d \ln \gamma_{1}\left(T, P_{s, 1}, x_{2}\right)+x_{2} d \ln \gamma_{2}^{\prime}\left(T, P_{s, 1}, x_{2}\right)=0
$$

At the vapor pressure $P_{s, 1}$ of the solvent, the Henry coefficient is rigorously accessible through determination of the limiting value of experimental (VLE) ratios of the fugacity of the solute over the corresponding mole fraction (see Fig. 1):

$$
H_{2,1}\left(T, P_{s, 1}\right)=\lim _{x_{2} \rightarrow 0}\left(f_{2}^{L} / x_{2}\right)=\lim _{x_{2} \rightarrow 0} \frac{y_{2} \phi_{2}^{V}\left(T, P, y_{2}\right) P}{x_{2}} .
$$

Thus, according to the prescription Eq.(27), $\mathrm{H}_{2,1}\left(T, \mathrm{P}_{\mathrm{S}, 1}\right)$ is obtained as the intercept in a graph of $\left(y_{2} \phi_{2} V_{P} / x_{2}\right)$ against $x_{2}$ at constant $T$. Since for $x_{2} \rightarrow 0$ also $y_{2} \rightarrow 0$, application of de 1'Hôpital's rule (see Fig. 1) yields several entirely equivalent expressions for the Henry coefficient $(24,31)$, relating it to limiting slopes. For instance 


$$
H_{2,1}\left(T, P_{s, 1}\right)=\lim _{x_{2} \rightarrow 0}\left(d f_{2}^{L} / d x_{2}\right)=\phi_{2}^{\infty} V_{s, 1} \lim _{x_{2} \rightarrow 0}\left(d y_{2} / d x_{2}\right),
$$

which is perhaps the most usefur version. Here $\phi_{2}^{\infty V}$ is the fugacity coefficient of component 2 at infinite dilution in the vapor phase.

Determination of the Henry coefficient is only the first step in a comprehensive reduction of gas-solubility data. Since actual solubility measurements are sometimes performed at several different pressures $P>P_{s, 1}$ and hence at different finite mole fractions $x_{2}$, they contain not only information on $\mathrm{H}_{2,1}$, but also on the composition dependence of the activity coefficient. The influence of total pressure upon liquid-phase fugacities has been separated formal1y from the influence of composition through Eqs. $(24,25)$, whence extraction of constant-pressure activity coefficients becomes feasible. The key relation for the determination of $\left\{\gamma_{2}^{\prime}\left(T, P_{s, 1}, x_{2}\right)\right\}$ at constant $T$ is a more compact and convenient form (31) of Eq.(24),

$$
\ln \left(\frac{y_{2} \phi_{2}^{V}\left(T, P, y_{2}\right) P}{x_{2} H_{2,1}\left(T, P_{s, 1}\right)}\right)-\int_{P_{s, 1}}^{P_{V}^{L}\left(T, P_{1} x_{2}\right)} \frac{V_{2}}{R T} d P=\ln \gamma_{2}^{\prime}\left(T, P_{s, 1}, x_{2}\right) .
$$

The argument of the logarithmic term on the lhs of Eq.(29) is a dimensionless group containing the experimental isothermal data, the Henry coefficient $\mathrm{H}_{2,1}\left(T, \mathrm{P}_{\mathrm{S}, 1}\right)$ al ready extracted therefrom, and the vapor-phase fugacity coefficient of the solute, which must be calculated from a suitable EOS, see Eqs. $(20,21)$. To proceed further, that is to say in order to evaluate the integral in Eq.(29), information is needed on the composition dependence as well as the pressure dependence of the partial molar volume $V_{2}^{L}$ in the liquid phase. These two terms may then be combined to yield constant - pressure activity coefficients for each data point, which in turn may be correlated with $x_{2}$ by any appropriate correlating equation. This is, then, the reward for exacting and tedious experimental work on the solubility of a gas in a liquid: the Henry coefficient $\mathrm{H}_{2,1}\left(\mathrm{~T}, \mathrm{P}_{\mathrm{S}, 1}\right)$ and a correlating equation for $\gamma_{2}^{\prime}\left(T, P_{s, 1}, x_{2}\right)$.

A final caveat concerns the extension of the methods just described to multisolute/multisolvent systems. The activity coefficient of any supercritical component may again be based on either the Henry coefficient or the fugacity of the pure solute in a hypothetical liquid state. Both approaches are thermodynamically equivalent, though implementation of the unsymetric formalism leads to somewhat more complex equations. The ensuing problems have been discussed in depth by Van Ness and Abbott (49), see also Ref.(24). Let it here suffice to present the general situation for a ternary solution in which a supercritical component 3 (the gas) is dissolved in a mixture of two solvents 1 and 2. For this case Fig. 2 shows schematically the surface

$$
\ln f=\sum_{i=1}^{3} x_{i} \ln \left(f_{i} / x_{i}\right)
$$

as a function of the composition at constant $T$ and $P$. The two curves $\operatorname{lnf}=\ln f\left(x_{3} ; x_{2}=0\right)$ and $\operatorname{lnf}=\operatorname{lnf}\left(x_{3} ; x_{1}=0\right)$ characterize the constituent binary solutions $[3,1]$ and $[3,2]$. For component 3 dissolved in solvent $i, H_{3, i}(T, P)$ is by definition the limiting value at constant $T$ and $P$ of the partial molar quantity $\ln \left(f_{3} / x_{3}\right)$ as $x_{3} \rightarrow 0$, and is thus given by the 
intercept on the $x_{3}=1$ axis of the tangent drawn at $\left(x_{3}=0, x_{i}=1\right)$. For the gas dissolved in a binary mixed solvent $[1+2]$ with composition $\left(x_{1}, x_{2}\right), \operatorname{lnH}_{3},[1+2](T, P)$ is obtained analogously. The curve results now from the intersection of the lnf surface with the vertical plane characterizing the constant composition ratio $x_{1} / x_{2}$, and the tangent is drawn at $\left(x_{3}=0, x_{1}, x_{2}=1-x_{1}\right)$, yielding the Henry coefficient aga in as the intercept on the $x_{3}=1$ axis. In the 1 imit $x_{3} \rightarrow 0$

$$
\ln H_{3,[1+2]} \equiv \lim _{x_{3} \rightarrow 0}\left(\ln \frac{f_{3}}{x_{3}}\right)=\ln f_{[1+2]}+\lim _{x_{3} \rightarrow 0}\left(\frac{\partial \ln f}{\partial x_{3}}\right)_{T, P, x_{1} / x_{2}},
$$

where $\operatorname{lnf}[1+2]$ is the fugacity of the binary (solute-free) solvent mixture [1+2]. Evidently, $\mathrm{H}_{3},[1+2]^{\mathrm{d}}$ epends on the composition of the mixed solvent $[1+2]$, and has of course the limiting values $\mathrm{H}_{3,1}$ for $\mathrm{x}_{1}=1$ and $\mathrm{H}_{3,2}$ for $\mathrm{x}_{2}=1$.

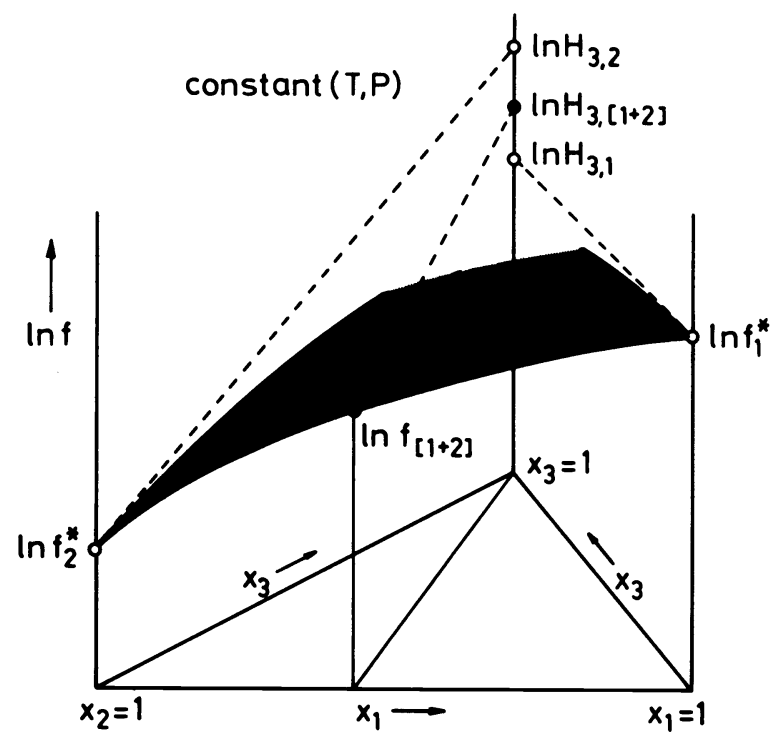

Fig. 2. Schematic representation of the lnf surface for a ternary solution of a gas, 3 , in the mixed solvent $[1+2]$ : the Henry coefficient in the pure solvent $i(=1$ or 2$)$ is $\mathrm{H}_{3, i}$, and in the mixed solvent it is $\mathrm{H}_{3,[1+2]} \cdot$

While the solubility of gases in mixed solvents is important in many industrial applications, relatively few experimental data are available. Thus, heavy use is made of prediction schemes which endeavor to correlate the multisolvent quantity $\mathrm{enH}_{\text {gas }},[1+2+3+\ldots]$ with the much more frequently known $\mathrm{lnH}_{\text {gas, } i}$ characterizing the solubility of the particular gas in solvent $i=1,2,3$ etc. In addition to work already cited, Refs. (57-60) further illustrate activities in this area.

We conclude this introduction to the thermodynamics of mixtures containing supercritical components with a section devoted entirely to various approximations to the exact relations obtained so far. These approximations are indispensable when application to experimental reality is desired.Additional details will be given together with the discussion of experimental techniques. Consider for instance the key relation Eq.(29). Though thermodynamically rigorous and fairly straightforward, this formalism for separating the 
influence of composition upon the liquid-phase fugacity from the influence of pressure is marred by the following $(22,31)$ :

(a) Rigorous evaluation of the Poynting term would require detailed knowledge of the pressure dependence as well as the composition dependence of the partial molar volume, and this at each temperature of interest. Such comprehensive information will be available only in very few cases; for the great majority of solutions, however, approximations at various levels of sophistication must be introduced $(1,22,24,31,61,62)$ to make the problem tractable. Similar comments apply to Eqs.(14),(16) etc. The situation is particularly unsatisfactory at high pressures and when approaching the critical region, where the Poynting corrections become significant.

(b) Frequently, the calculation of $\phi_{2}^{V}$ cannot be based on experimental results, say second and third virial coefficients (63), but must use semi-empirical correlations, the reliability of which may not always be high. This may impede satisfactory reduction of data obtained at elevated pressures $(64,65)$.

(c) With few exceptions, typical gas solubility measurements do not cover large composition ranges. At the same time, experimental scatter often tends to obscure the composition dependence of the derived constant-pressure activity coefficients. Thus for purely practical reasons, the correlating equations for $\gamma_{2}^{\prime}$ usually contain only few adjustable parameters, that is to say very rarely more than two $(1,66)$.

Against this background several popular approximations to the key relation Eq.(29) will be given in order of decreasing restrictiveness. The assumption $\phi_{2}^{V}=1$ (the vapor phase behaves as an ideal-gas mixture), together with $\gamma_{2}^{\prime}\left(T, P_{s .1}, x_{2}\right)=1$ (usually quite reasonable for small solubilities) and ignoring the Poynting term (acceptable for pressures $P \approx P_{s, 1}$ well below the critical region) leads to the simplest and most familiar relation

$$
P_{2} \equiv y_{2} P=x_{2} H_{2,1}
$$

which is often called "Henry's law". A series of similar approximations to Eq.(25) results in "Raoult's law" for the solvent,

$$
P_{1} \equiv y_{1} P=x_{1} P_{s, 1}
$$

If only the simplification concerning the vapor phase is relaxed, we obtain for the solute

$$
y_{2} \phi_{2}^{v}\left(T, P, y_{2}\right) P=x_{2} H_{2,1} \text {. }
$$

Adding the Poynting term with $V_{2}^{L}\left(T, P, x_{2}\right)=V_{2}^{\infty L}\left(T, P_{S, 1}\right)$, yet still retaining $\gamma_{2}^{\prime}=1$, independent of composition, yields

$$
\ln \left(\frac{y_{2} \phi_{2}^{v}\left(T, P, y_{2}\right) P}{x_{2} H_{2,1}\left(T, P_{s, 1}\right)}\right)=\frac{\left(P-P_{s, 1}\right) V_{2}^{\infty L}\left(T, P_{s, 1}\right)}{R T} .
$$

This expression is known as the kricheusky-Kasarnousky equation (67). For a long time it has been used for the determination of $v_{2}^{\infty L}$ from gas solubility measurements at elevated pressures and accounts, in fact, for a large portion of the existing data. However, the mole fraction solubility may then be already appreciable and hence the assumptions $\gamma_{2}^{\prime}=1$ and $V_{2}^{L}=V_{2}^{\infty L}$ too severe. Values for $v_{2}^{\infty L}$ obtained in this way should always be regarded with caution and may be unreliable $(68,69)$. The preferred experimental method for determining $v_{2}^{\infty L}$ is either precision densimetry (70) or dilatometry (71) at very small mole fractions.

As concerns the modeling of the composition dependence of $\gamma_{2}^{\prime}$, the correlating equation has 
to be compatible with the number and the precision of the experimental data points. Because of the interconvertability of symmetrically and unsymmetrically normalized activity coefficients, Eqs.(11) through (13), the selection of such correlations usually follows rather closely the well established recipes for the symmetrically normalized activity coefficients. The simplest possibility corresponds to the two-suffix Margules equation, that is to say for the constant-pressure activity coefficients at $P_{s, 1}$ and $T$ we obtain

$$
\ln \gamma_{1}=A x_{2}^{2}, \ln \gamma_{2}^{\prime}=A\left(x_{1}^{2}-1\right) .
$$

Insertion into Eq.(29) and maintaining the same level of approximation with respect to $V_{2}^{L}$ gives

$$
\ln \left(\frac{Y_{2} \phi_{2}^{V}\left(T, P, y_{2}\right) P}{x_{2} H_{2,1}\left(T, P_{s, 1}\right)}\right)-\frac{\left(P-P_{s, 1}\right) V_{2}^{\infty L}\left(T, P_{s, 1}\right)}{R T}=A\left(x_{1}^{2}-1\right),
$$

which is known as the Kricheusky - Ilinskaya equation $(72,73)$. There can be 1 ittle doubt that even Eq.(37) is not particularly realistic at high pressures and/or high solubility. However, we emphasize again that an indispensible prerequisite for the use of more elaborate correlating equations is the availability of experimental data on the composition dependence of the partial molar volume as well as on its pressure dependence.

The magnitude of the Poynting correction, evaluated with a generally applicable liquid-phase EOS, is indicated by the following specific exampie. Consider a fictitious liquid, at $298.15 \mathrm{~K}$, with molar volume $V_{\mathrm{S}}^{* \mathrm{~L}}=120 \mathrm{~cm}^{3} \mathrm{~mol}^{-1}$ and isothermal compressibility $\mathrm{B}_{\mathrm{T}, \mathrm{s}}^{* \mathrm{~L}}=10^{-9} \mathrm{~Pa}^{-1}$, and let the pressure dependence of $V^{*} \mathrm{~L}$ be accounted for by the modified Tait equation (22, $26,31,74)$, which is satisfactory for pressures up to several tens of megapascals. Upon insertion into Eq.(15) and integration

$$
D_{M T E}=\exp \left\{\frac{V_{s}^{* L}}{R T} \frac{\left(1+m \beta_{T, s}^{* L} \Delta P\right)^{\frac{m-1}{m}}-1}{(m-1) \beta_{T, s}^{* L}}\right\},
$$

where $\Delta P=P-P_{S}$, and $m$ is a pressure-independent parameter. For many organic 1 iquids experimental values cluster around $m=10$, with very small temperature dependence $(74,75)$. For an applied pressure $\Delta \mathrm{P}=0.2 \mathrm{MPa}$ we obtain $\mathcal{P}_{\mathrm{MTE}}=1.01$, and for $\Delta \mathrm{P}=2 \mathrm{MPa}$ the result is $\gamma_{M T E}=1.10$, quite a significant correction. Qualitatively similar comments apply for the solute.

Whatever method for determining $\mathrm{H}_{2,1}\left(T, \mathrm{P}_{S, 1}\right)$ is selected, say for instance recipes Eq.(27) or Eq.(28), evaluation from an experimental isothermal data set requires a vapor-phase EOS for calculating the fugacity coefficient. The majority of gas solubility measurements are in the low to moderate pressure domain, say with $P$ not exceeding several megapascals. Hence for many systems the virial equation

$$
Z^{V} \equiv P / \rho^{V} R T=1+B \rho^{V}+C\left(\rho^{V}\right)^{2}+\cdots
$$

is convenient $(26,31)$, and often yields entirely satisfactory results even when truncated after the term which is 7 inear in molar density $\rho$. For a mixture of $K$ components, each with mole fraction $y_{i}$.

$$
B(T,\{y\})=\sum_{i}^{K} \sum_{j}^{K} y_{i} y_{j} B_{i j}(T),
$$




$$
C(T,\{y\})=\sum_{i}^{K} \sum_{j}^{K} \sum_{k}^{K} y_{i} y_{j} y_{k} C_{i j k}(T) \text { etc. }
$$

Coefficients with identical subscripts refer to pure substances, whereas mixed subscripts designate composition-independent interaction virial coefficients (or cross-coefficients) characterizing the molecular interaction between molecules of species $i$ with those of species $j\left(B_{i, j}\right)$, of species $i$ with those of species $j$ and $k\left(C_{i j k}\right)$ and so forth. They are functions of temperature only. Insertion of Eqs.(39-41) into Eq.(20) yields for a two-component mixture

$$
\begin{aligned}
& \ln \phi_{2}^{v}=2 \rho^{v}\left(y_{2} B_{22}+y_{1} B_{12}\right)+\frac{3}{2}\left(\rho^{v}\right)^{2}\left(y_{2}^{2} C_{222}+2 y_{1} y_{2} C_{122}+y_{1}^{2} C_{112}\right)-\ln Z^{v}, \\
& \ln \phi_{2}^{\infty V}=2 \rho_{1}^{* V} B_{12}+\frac{3}{2}\left(\rho_{1}^{* V}\right)^{2} C_{112}-\ln Z_{1}^{* V} .
\end{aligned}
$$

Unfortunately, experimental information on third virial coefficients is rather limited and one has to rely heavily on correlation methods, such as those advanced by Chueh and Prausnitz (76), or more recently by De Santis and Grande (77), and Orbey and Vera (78). This, and the computational convenience associated with a volume-explicit rather than a pressure-explicit EOS, leads to the widely used approximation for low pressures

$$
Z^{V}=1+B P / R T \text {, }
$$

where $B$ of the mixture is again given by Eq. (40). The corresponding expression for the fugacity coefficient is now

$$
\begin{aligned}
& \ln \phi_{2}^{V}=\frac{P}{R T}\left(B_{22}+y_{1}^{2} \delta_{12}\right), \\
& \ln \phi_{2}^{\infty V}=\frac{P}{R T}\left(2 B_{12}-B_{11}\right),
\end{aligned}
$$

where $\delta_{12} \equiv 2 B_{12}-\left(B_{11}+B_{22}\right)$. We emphasize that the quite popular rule of thumb

$$
\phi_{2}^{v}\left(T, P, y_{2}\right)=\phi_{2}^{* V}(T, P)
$$

may frequently be a rather unsatisfactory assumption (22), and is in general inapplicable

for the evaluation of $\phi_{2}^{\infty}$. Eq. (47) can be justified only if the vapor phase is an ideal solution.

\section{EXPERIMENT}

Advances in experimental technique for the determination of Henry coefficients may be classified as follows:

(a) novel designs of apparatus which significantly improve experimental precision and accuracy;

(b) designs which increase the accessible pressure and temperature ranges of already existing instruments;

(c) efforts towards simplifying and accelerating data acquisition.

In this article only recent contributions to (a) will be considered. Some of the older, more popular types of apparatus have been reviewed in detail by Battino and Clever (79) in 1966, and a decade later in 1975 (8); see also Refs. $(6,13,17,21,25)$. 
The most significant recent advance belonging to group (a) is undoubtedly due to Benson and Krause (BK) $(80,81)$. They use an analytical method in which the composition of the 1 iquid phase and of the vapor phase in equilibrium is determined via classical PVT measurements. The precision (and accuracy) which may be achieved with BK-type equipment surpasses that of any previous design, including the one of Cook and Hanson (82). A schematic representation of the experimental situation $(31,81,83-85)$ is provided by Fig. 3 . The flow diagram contains the essential parts of the apparatus as well as the auxiliary thermodynamic quantities, which have to be either measured separately, or extracted from the literature, or estimated. The average random error of $\mathrm{H}_{2,1}\left(\mathrm{~T}, \mathrm{P}_{\mathrm{S}, 1}\right)$ obtained in this way is usually about $\pm 0.05 \%$. The method's reliability has been impressively demonstrated by the reported interlab accord on oxygen solubility in water: between 275 and $328 \mathrm{~K}$, the difference between the data reported by Benson et a1. (81) and those reported by Rettich et al. (83-85) amounted to about $0.1 \%$.

As shown in Fig. 3, the essential parts of this apparatus are a degassing device (86), an equilibrator $(81,83$ ), an extractor (same design as for degassing), the Töpler pump (87) for transferring the dry gas to the manometric system, the high-precision manometric system itself (PVT-measurements) and, of course, powerful thermostats (temperature drift $\leqslant \pm 0.003 \mathrm{~K}$ during $24 \mathrm{~h}$ ) and platinum resistance thermometers. Quantities measured are the temperature at equilibrium, and the amounts of gas $n_{2}^{L}$ and $n_{2}^{V}$ contained in precisely known volumes of the liquid solution, $v^{L}$, and of the vapor phase, $v^{V}$. As was shown in Ref.(83), Henry coefficients of sparingly soluble gases may be obtained according to

$$
\begin{aligned}
& H_{2,1}\left(T, P_{s, 1}\right)=\lim _{x_{2} \rightarrow 0}\left[h_{2,1} Z^{V}\left(T, P, Y_{2}\right) \phi_{2}^{V}\left(T, P, y_{2}\right)\right], \\
& h_{2,1}=\left(n_{2}^{V} / n_{2}^{L}\right)\left(\hat{v}^{L} / v^{V}\right) R T / V_{1}^{* L}, \\
& \hat{v}^{L} \simeq v^{L}-n_{2}^{L}\left(V_{2}^{\infty L}-V_{2}^{* L}\right) .
\end{aligned}
$$

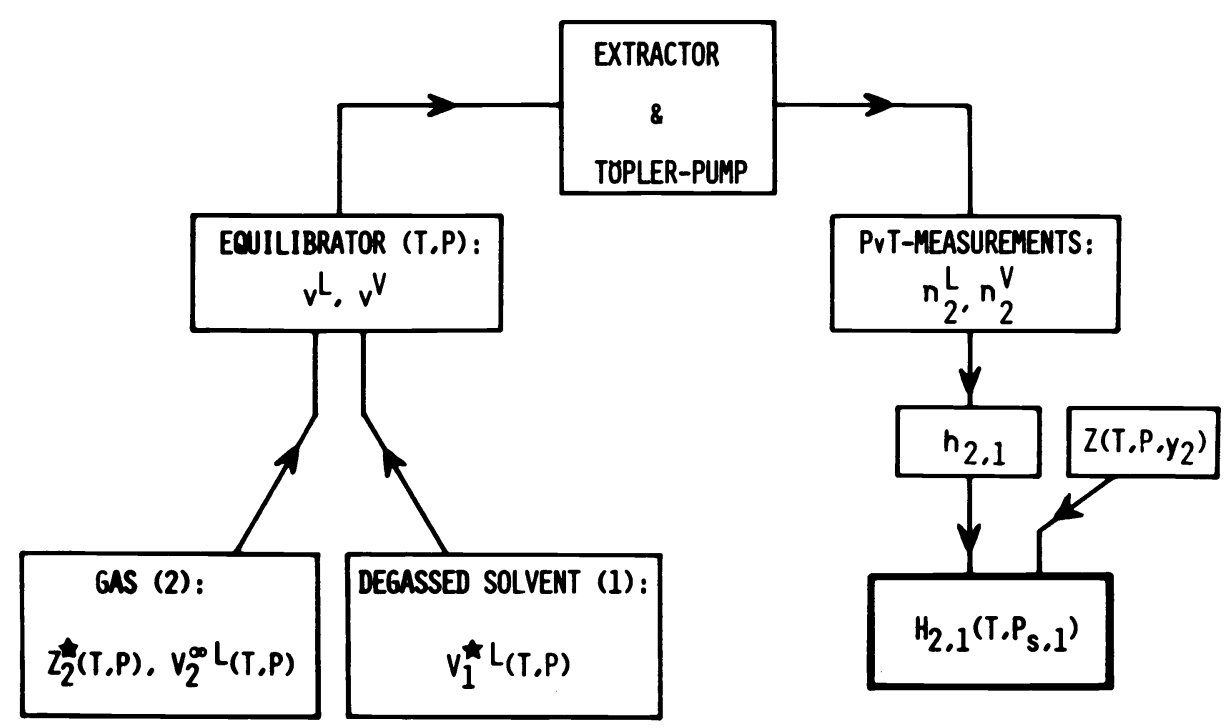

Fig. 3. Determination (schematic) of Henry coefficients $H_{2,1}\left(T, P_{S, 1}\right.$ ) with a BK-type apparatus $(81,83)$. Auxiliary quantities needed for rigorous data reduction are also shown $(31,83-85)$. 
Note that the total equilibrium pressure $P$ does not appear explicitely in Eq. (48). It has to be known, however, for the evaluation of the correction term $z^{V} \phi_{2}^{V}$, and is obtained by an iterative procedure described in detail in Ref.(83).

As already indicated above, for gaseous mixtures at low pressures the virial EOS in its volume-explicit form is convenient. While there is often sufficient information on the puresubstance virial coefficients $B_{i j}$, experimental results on the cross-coefficients $B_{12}$ are frequently lacking (63). Cross-coefficients may be estimated with reasonable confidence by several well-established correlations, such as the Hayden-0'Connell method (88) or the Pitzer-Curl-Tsonopoulos corresponding-states method $(89,90)$. When using the latter, the reduced pure-substance virial coefficient at a reduced temperature $T_{r}$ is given by

$$
\frac{B P_{c}}{R T_{c}}=B^{(0)}\left(T_{r}\right)+\omega B^{(1)}\left(T_{r}\right) \text {, }
$$

where $B^{(0)}$ and $B^{(1)}$ are polynomials in $T_{r}^{-1}$, and $\omega$ is the acentric factor. It is assumed that the same relation holds for the cross-coefficient $B_{12}$, but with characteristic parameters (interaction parameters) $T_{c, 12}, P_{c, 12}$ and $\omega_{12}$ replacing the pure-substance quantities $T_{c}, P_{c}$ and $\omega$, to which they are related by conventional recipes known as combining rules. Specifically, the reduced temperature is now $T_{r, 12} \equiv T / T_{c, 12}$, and

$$
\begin{aligned}
& T_{c, 12}=\left(1-k_{12}\right)\left(T_{c, 1} T_{c, 2}\right)^{1 / 2}, \\
& P_{c, 12}=4 T_{c, 12}\left(P_{c, 1} V_{c, 1} / T_{c, 1}+P_{c, 2} V_{c, 2} / T_{c, 2}\right)\left(V_{c, 1}^{1 / 3}+V_{c, 2}^{1 / 3}\right)^{-3}, \\
& \omega_{12}=\left(\omega_{1}+\omega_{2}\right) / 2 .
\end{aligned}
$$

The quantity $k_{12}$ is another binary interaction parameter (usually much smaller than unity). It is similar to the binary interaction parameters used in the more fundamental combining rules for unlike energy parameters of two-parameter pair potentials $(26,91,92)$. Mixture compressibility factor $z^{V}$ and component fugacity coefficient $\phi_{2}^{V}$ may then be calculated by Eqs. $(40,44,45)$. Alternatively, one may use any appropriate analytical EOS to obtain $z^{V} \phi_{2}^{V}$. Examples for calculations of this kind have been presented in Refs.(93) and (94). In the former, a modified Redlich-Kwong equation is used, while the latter utilizes a perturbedhard-sphere EOS similar to that introduced by Carnahan and Starling (95).

In our method $(31,83-85)$ of determining $\mathrm{H}_{2,1}\left(T, \mathrm{P}_{\mathrm{S}, 1}\right)$, the partial molar volume at infinite dilution has to be known. Recent measurements with a vibrating-tube densimeter (70) yielded $\mathrm{V}_{2}^{\infty} \mathrm{L}$ for 20 fluids (about half of them supercritical) dissolved in water; a dilatometric method was used in Ref.(71) to obtain this quantity for several gases $\left(\mathrm{CH}_{4}, \mathrm{C}_{2} \mathrm{H}_{6}\right.$ etc.) in $n$-alkanes and 1-alkanols. $V_{2}^{\infty L}$ in liquid water is well correlated with $V_{c, 2}$, that is to say at $298.15 \mathrm{~K}$ our results are represented to within $\mathrm{ca} . \pm 10 \%$ by $\mathrm{v}_{2}^{\infty \mathrm{L}} / \mathrm{cm}^{\mathrm{C}} \mathrm{mol}^{-1}=10.74$ $+0.2683 \mathrm{v}_{\mathrm{c}, 2} / \mathrm{cm}^{3} \mathrm{~mol}^{-1}$. For the noncondensables this is comparable to the performance of the Brelvi-0'Connell correlation (96), which should not be used at temperatures substantially below the critical temperature of the solute $T_{c, 2}$. Scaled particle theory has been used by Pierotti $(12,97)$ and Wilnelm et al. (14), amongst others, to calculate $V_{2}^{\infty L}$ for nonpolar and polar gases in both nonpolar and polar solvents according to

$$
V_{2}^{\infty L}=V_{\text {CAV }}+\beta_{T, s, 1}^{* L}\left(G_{I N T}+R T\right) .
$$

Here $V_{C A V}=\left(\partial G_{C A V} / \partial P\right)_{T}$, and $G_{C A V}$ and $G_{I N T}$ are the partial molar Gibbs energy of cavity 
formation (98) and interaction $(12,14,97,99,100)$, respectively. Agreement with experiment is satisfactory in most cases. For a review of the literature on $V_{2}^{\infty L}$ see Handa and Benson (62).

Over 1 imited ranges of $T$, the temperature dependence of $\mathrm{H}_{2,1}\left(T, \mathrm{P}_{S, 1}\right)$ is usually adequately represented by either the Clarke-Glew (CG) equation (101)

$$
\ln \left(H_{2,1} / \mathrm{Pa}\right)=A_{0}+A_{1}(T / K)^{-1}+A_{2} \ln (T / K)+A_{3}(T / K)+A_{4}(T / K)^{2}+\cdots
$$

or by the BK equation $(80,81)$

$$
\ln \left(H_{2,1} / P a\right)=\sum_{i=0}^{n} a_{i}(T / K)^{-i} .
$$

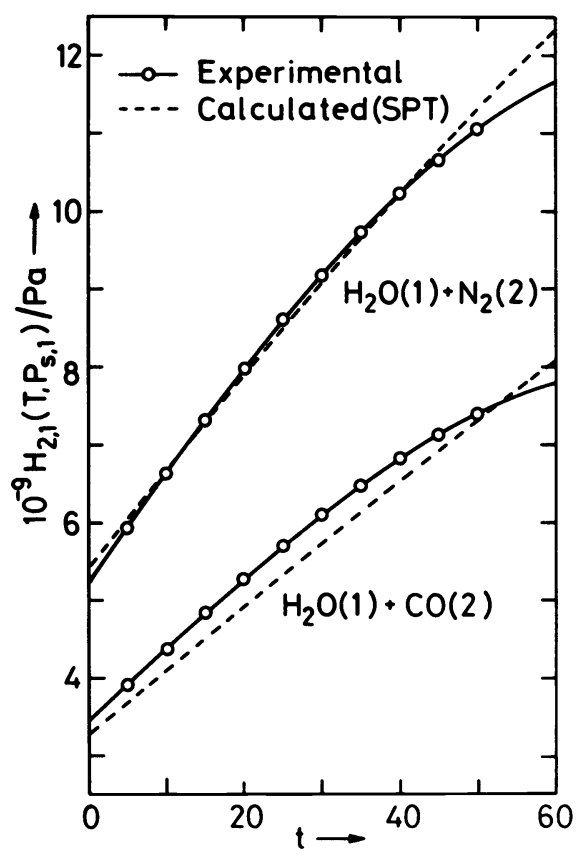

Fig. 4. Henry coefficients $\mathrm{H}_{2,1}\left(T, \mathrm{P}_{\mathrm{S}, 1}\right)$ for $\left(\mathrm{H}_{2} \mathrm{O}+\mathrm{N}_{2}\right)$ and $\left(\mathrm{H}_{2} \mathrm{O}+\mathrm{CO}\right)$ as functions of temperature: $t=T / K-273.15$. $O$, experimental results; either CG or BK smoothing equations; - - , obtained via scaled particle theory $(84,85)$.

Fig. 4 shows measured Henry coefficients for $\mathrm{CO}$ and $\mathrm{N}_{2}$ dissolved in water $(84,85)$ as a function of temperature, the correlations provided by the appropriate smoothing equations (CG or BK), and results obtained by application of scaled particle theory in its simplest version $(12,14,97,99,100)$. Substantial improvement of the temperature dependence of $\mathrm{H}_{2,1}$ (for instance, reasonably accurate prediction of the usually observed maximum of the curve $\mathrm{H}_{2, \uparrow}$ vs. T) is possible by introducing the concept of effective, hence temperature-dependent, hard-sphere diameters (102) into the formalism, as recently shown by Prausnitz et al. (46, 103).

With very few exceptions precision measurements of $\mathrm{H}_{2,1}\left(T, \mathrm{P}_{\mathrm{S}, 1}\right)$ over sufficiently large ranges of temperature constitute the only source of information on enthalpies of solution, $\Delta H_{2}^{\circ}$, and a fortiori on heat capacity changes upon solution, $\Delta C_{\mathrm{p}, 2}^{\circ}=\left(\partial \Delta \mathrm{H}_{2}^{\circ} / \partial \mathrm{T}\right)_{\mathrm{p}}$, of sparingly soluble gases in liquids $(14,104,105)$, see also Refs. $(26,31)$. Specifically, 


$$
\Delta H_{2}^{\circ} / R T=\left(H_{2}^{\infty L}-H_{2}^{\circ V}\right) / R T=-\frac{T}{H_{2,1}\left(T, P_{s, 1}\right)} \frac{d H_{2,1}\left(T, P_{s, 1}\right)}{d T}+\frac{V_{2}^{\infty L}}{R} \frac{d P_{s, 1}}{d T},
$$

where $\mathrm{H}_{2}^{\infty}$ is the partial molar enthalpy of the gas at infinite dilution in the solvent, and $\mathrm{H}_{2}^{\mathrm{l}}$ is the molar enthalpy of pure component 2 in the ideal-gas state. The first term on the rhs of Eq.(56) is obtained from one of the selected fitting equations. The temperature dependence of the vapor pressure of the solvent may be calculated from any suitable vapor pressure correlation, for instance from the Antoine equation, the Lee-Kesler equation (for nonpolar liquids) (106) or the Scott-0sborne equation (107). For temperatures far below $T_{c, 1}$, the second term on the rhs of Eq.(56) will frequently be rather small as compared to the first term. Eq.(56) evidently provides a set of values $\Delta H_{2}^{\circ}\left(T, P_{s, 1}\right)$, which yields, by an argument analogous to that used above, the heat capacity change upon solution.

The Ostwald coefficient $L_{2,1}$ is another widely used practical measure of the solubility of gas 2 in solvent 1 (108). Let the conventional Ostwald coefficient be defined by

$$
L_{2,1}(T, P) \equiv\left(c_{2}^{L} / c_{2}^{v}\right)_{\text {equil }},
$$

where $c_{2} \equiv n_{2} / v$, with the appropriate superscript, is the amount-of-substance concentration (or simply, concentration) of solute 2 either in the liquid-phase solution or in the coexisting vapor-phase solution at $(T, P)$. Its limiting value for vanishingly small concentration is denoted by

$$
L_{2,1}^{\infty}=\lim _{\substack{c_{2}^{L} \rightarrow 0 \\ P \rightarrow P_{s, 4}}} L_{2,1}(T, P)=\lim _{\substack{c_{2}^{L} \rightarrow 0 \\ P \rightarrow P_{s, 1}}}\left(c_{2}^{L} / C_{2}^{V}\right)_{\text {equil }} .
$$

Eq. (57) in conjunction with the equilibrium condition formulated on the bas is of Henry's law yields (22), after some algebraic manipulation, the rigorous relation

$$
L_{2,1}(T, P)=\frac{R T}{H_{2,1}(T, P) V^{L}\left(T, P, x_{2}\right)} \frac{Z^{V}\left(T, P, y_{2}\right) \phi_{2}^{V}\left(T, P, y_{2}\right)}{\gamma_{2}^{\prime}\left(T, P, x_{2}\right)},
$$

where $V^{L}\left(T, P, x_{2}\right)$ is the molar volume of the liquid solution. Hence in the limit of $c_{2}^{L} \rightarrow 0$ we obtain, with $\lim _{c_{2}^{L} \rightarrow 0} V^{L}\left(T, P, x_{2}\right)=V_{1}^{* L}\left(T, P_{S, 1}\right)$,

$$
L_{2,1}^{\infty}=\frac{R T}{H_{2,1}\left(T, P_{s, 1}\right) V_{s, 1}^{* L}} Z_{s, 1}^{* V} \phi_{2}^{\infty} V\left(T, P_{s, 1}\right) \text {. }
$$

At low to moderate pressures Eq.(43) may be applied, whereby

$$
Z_{s, 1}^{* V} \phi_{2}^{\infty} V\left(T, P_{s, 1}\right)=\exp \left\{2 \rho_{s, 1}^{* V} B_{12}+\frac{3}{2}\left(\rho_{s, 1}^{* V}\right)^{2} C_{112}\right\} \text {. }
$$

Alternatively, we may use the virial equation in its volume-explicit form, whence after series expansion

$$
Z_{s, 1}^{* V} \phi_{2}^{\infty V}\left(T, P_{s, 1}\right)=1+2\left(\frac{P_{s, 1}}{R T}\right) B_{12}+\left(\frac{P_{s, 1}}{R T}\right)^{2} B_{11}\left(2 B_{12}-B_{11}\right) .
$$

As reported by Wilhelm (22), Eq.(60) provides a rigorous expression for the limiting value of the Henry coefficient as $T \rightarrow T_{c, 1}$ and $P_{s, 1} \rightarrow P_{c, 1}$ :

$$
\lim _{T \rightarrow T_{c, 1}} H_{2,1}\left(T, P_{s, 1}\right)=P_{c, 1} \phi_{2}^{\infty} V_{c}\left(T_{c, 1}, P_{c, 1}\right)
$$


which equation was also given by Beutier and Renon (109). It must be incorporated in any rational wide-temperature range correlation for $H_{2, \uparrow}\left(T, P{ }_{S, \uparrow}\right)$ extending up to the critical region. In particular we note that the empirical extrapolation recipe of Hayduk and Laudie $(110)$ is in variance with Eq. (63).

The Ostwald coefficient is of central importance in the theory of hydrophobic (solvophobic) phenomena. Following Ben-Naim (18), when discussing pairwise hydrophobic interaction (HI) we refer to the indirect part $\delta G \mathrm{HI}(r)$ of the Gibbs energy change $\Delta G(r)$ required to bring the solute particles from fixed positions at infinite separation in water to some close distance $r$ at constant temperature and pressure. In other words, we are interested in the solventinduced contribution augmenting the direct part that is due to the solute-solute pair potential $U_{S S}(r)$,

$$
\Delta G(r)=U_{S S}(r)+\delta G^{H I}(r) \text {. }
$$

The link with experimentally accessible quantities is established by the approximate relation

$$
\delta G^{H I}\left(r=r_{C-C}\right)=\Delta \mu_{C_{2} \mathrm{H}_{6}, \mathrm{H}_{2} \mathrm{O}}^{\circ}-2 \Delta \mu_{\mathrm{CH}_{4}, \mathrm{H}_{2} \mathrm{O}}^{0} \text {, }
$$

where $r_{C-C}=0.1533 \mathrm{~nm}$ is the carbon-carbon distance in ethane and

$$
\Delta \mu_{i, H_{2} \mathrm{O}}^{\circ}=-\mathrm{RT} \ln L_{i, \mathrm{H}_{2} \mathrm{O}}^{\infty}, i=\mathrm{CH}_{4} \text { or } \mathrm{C}_{2} \mathrm{H}_{6} \text {. }
$$

The approximation indicated by Eq.(65) is easily generalized to discuss HI among many solute particles $(18,111)$.

\section{CONCLUDING REMARKS}

Quantitative investigation of the solubility of gases in liquids has a long and well established tradition in physical chemistry. Essentially it started in the fifties of the last century with the work of Bunsen (112), and throughout the years many a distinguished scientist has contributed to this subject. One can only marvel about the careful experimental work of some of the early researchers; for instance about Winkler's contributions (113) a1most a century ago, which are still quite acceptable ( $\pm 1 \%$ ) in the majority of cases. The assortment of modern instrumentation accessible to today's experimentalist, however, has now made possible the study of highly dilute binary solutions of gases in liquids with unparalleled precision, accuracy and speed over wide ranges of temperature and pressure. Cross-fertilization with other disciplines, for instance with calorimetry, is becoming increasingly important $(104,105)$. In fact, one of the objectives of this article was to indicate new and active interdisciplinary topics (see the Introduction); while our own perception of their relative importance may not be shared by all, it appears safe to state that they will greatly stimulate applied research in the coming decade.

This review was primarily concerned with the rigorous thermodynamic formalism relevant to VLE involving supercritical compounds, and its rational implementation in high-precision experimental work directed towards the determination of Henry coefficients and related quantities. Alternatives to the classical approach have been indicated, for instance the use of an EOS valid for both the liquid and the vapor phases. This method may gradually become more prominent when relatively simple solutions are considered. Yet as long as the scientist's interest is focused on phenomena involving significantly anisotropic molecules 
in dilute solutions, in particular in aqueous solutions, the Henry's law approach appears to be naturally superior to the others, and it is hard to imagine its replacement. Little space was devoted to experimental details, and recent theoretical advances have been indicated only briefly. Our understanding of nonpolar, nonassociated liquids and of "simple" solutions has increased considerably during the last decade $(7,13,15,17,25,114-118)$. This is much less so for liquid water, and aqueous solutions even of rather simple solutes, such as hydrocarbons, remain a major challenge to a statistical-mechanical interpretation of solubility phenomena. High-precision measurements of the kind discussed here in the experimental section evidently occupy a key position in the development of new theoretical approaches.

\section{REFERENCES}

1. J.M. Prausnitz, Molecular Thermodynamics of Fluid-Phase Equilibria, Prentice Ha11, Englewood Cliffs, N.J. (1969).

2. J.H. Hildebrand, J.M.Prausnitz and R.L. Scott, Regular and Related Solutions, Van Nostrand Reinhold, New York (1970).

3. F. Franks, editor, Water. A Comprehensive Treatise, Plenum Press, New York, vol.1 (1972) and later.

4. M.H. Klapper, Adv. Chem. Phys. 23, 55-132 (1973).

5. E. Wilhelm and R. Battino, Chem. Rev. 73, 1-9 (1973).

6. M.L. McGlashan, editor, Specialist Periodical Reports: Chemical Thermodynamics, The Chemical Society, London, vol.1 (1973) and vol.2 (1978).

7. K. Singer, editor, Specialist Periodical Reports: Statistical Mechanics, The Chemical Society, London, vol.1 (1973) and vol.2 (1975).

8. H.L. Clever and R. Battino in Solutions and Solubilities, vol.8, part 1 of Techniques of Chemistry, M.R.J. Dack, editor, chapter 7, pp. 379-441. Wiley, New York (1975).

9. F.W. Getzen in Solutions and Solubilities, vol.8, part 2 of Techniques of Chemistry, M.R.J. Dack, editor, chapter 15, pp. 363-436. Wiley, New York (1976).

10. W. Gerrard, (a) Solubility of Gases in Liquids. A Graphic Approach, Plenum Press, New York (1976); (b) Gas Solubilities, Pergamon Press, Oxford (1980).

11. Landolt-Börnstein, 4.Band, 4.Tei1, Bestandtei1 c, Gleichgewicht der Absorption von Gasen in Flüssigkeiten, Teil c1: Absorption in Flüssigkeiten von niedrigem Dampfdruck, and Teil c2: Absorption in Flüssigkeiten von hohem Dampfdruck, Springer-Verlag, Berl in (1976 and 1980).

12. R.A. Pierotti, Chem. Rev. 76, 717-726 (1976).

13. E. Wilhelm, Fortschr. Verfahrenstechn. A, Grunde. Verfahrenstechn. 15, 21-54 (1977).

14. E. Wilhelm, R. Battino and R.J. Wilcock, Chem. Rev. 77, 219-262 (1977).

15. S. Goldman, Acc. Chem. Res. 12, 409-415 (1979).

16. A.S. Kertes, editor, Solubility Data Series (IUPAC), Pergamon Press, Oxford, vol.1 (1979) and 1ater.

17. E. Wilhe1m, Progr. Chem. Eng. A, Fundam. Chem. Eng. 18, 21-56 (1980).

18. A. Ben-Naim, Hydrophobic Interactions, Plenum Press, New York (1980).

19. C. Tanford, The Hydrophobic Effect. Formation of Micelles and Biological Membranes, 2nd edition, Wiley, New York (1980).

20. J.M. Prausnitz, T.F. Anderson, E.A. Grens, C.A. Eckert, R. Hsieh and J.P. O'Conne11, Computer Calculations for Multicomponent Vapor-Liquid and Liquid-Liquid Equilibria, Prentice Ha11, Englewood Cliffs, N.J. (1980).

21. K.N. Marsh, (a) Ann. Rep. Prog. Chem., Sect. C 77, 101-120 (1980);

(b) Pure Appl. Chem. 55, 467-478 (1983).

22. E. Wilhelm in Nitrogen and Air, vol.10 of Solubility Data Series (IUPAC),

R. Battino, volume editor, pp. 20-28. Pergamon Press, Oxford (1982).

23. J.C. Charpentier, Trans. Inst. Chem. Engrs. 60, 131-156 (1982).

24. H.C. Van Ness and M.M. Abbott, Classical Thermodynamics of Nonelectrolyte Solutions, McGraw-Hi11, New York (1982).

25. E. Wilhe1m, Progr. Chem. Eng. A, Fundam. Chem. Eng. 21, 45-93 (1983).

26. E. Wilhelm, Thermochim. Acta 69, 1-44 (1983).

27. J.M.H. Levelt Sengers, Pure Appe. Chem. 55, $437-453$ (1983).

28. L.G. Hepler, Pure Appe. Chem. 55, 493-504 (1983).

29. I. Wadsö, Pure Appl. Chem. 55, 515-528 (1983).

30. E. Berecz and M. Baila-Achs, Gas-Hydrates, El Sevier, Amsterdam (1983).

31. E. Wilhe1m in Mixtures of Non-Electrolytes and Intermolecular Interactions,

H. Schuberth, editor, in press. Martin-Luther-Universität Halle-Wittenberg, Halle (1984).

32. J. Wisniak and M. Herskowitz, Solubility of Gases and Solids. A Literature Source Book, 
El sevier, Amsterdam (1984).

33. E. Wilhelm and R. Battino, J. Chem. Thermodyn. 3, 761-768 (1971).

34. J.G. Riess and M.Le Blanc, Angew. Chem. 90, 654-668 (1978).

35. N. Schnoy, F. Pfannkuch and H. Beisbarth, Anaesthesist 28, 503-510 (1979).

36. R.J. Wilcock, R. Battino, W.F. Danforth and E. Wilhelm, J. Chem. Thermodyn. 10, 817-822 ( 1978).

37. (a) K.W. Miller, Fed. Proc., Fed. Am. Soc. Exp. Biol. 36, 1663-1667 (1977); (b) J.F. Sauter, L. Brasweil, P. Wankowicz and K.W. Miller, Underwater Physiol. 7 , 629-637 (1981); (c) R.A. Smith, E.G. Porter and K.W. Miller, Biochem. Biophys. Acta 645, 327-338 (1981); (d) A.S. Janoff and K.W. Miller, Biol. Membr. 4, 417-476 (1982).

38. M.H. Abraham, M.J. Kamlet, R.W. Taft and P.K. Weathersby, J. Am. Chem. Soc. 105, 6797-6801 ( 1983$)$.

39. T. Park, T.R. Rettich, R. Battino, D. Peterson and E. Wilhelm, J. Chem. Eng. Data 27 , $324-328$ (1982).

40. J.A. Roth and D.E. Sullivan, Ind. Eng. Chem. Fundam. 20, 137-140 (1981).

41. (a) V01.7 of Ref.(16), oxygen and Ozone, R. Battino, volume editor (1981);

(b) R. Battino, T.R. Rettich and T. Tominaga, J. Phys. Chem. Ref. Data 12, 163-178 (1983).

42. O.R. Rivas and J.M. Prausnitz, AIC'tE J. 25, 975-984 (1979).

43. R.W. Rousseau, J.N. Matange and J.K. Ferre11, AIChE J. 27, 605-613 (1981).

44. K. Takeuchi, K. Matsumura and K. Yaginuma, Fluid Phase Equil. 14, 255-263 (1983).

45. H.M. Sebastian, H.M. Lin and K.C. Chao, AICt.E J. 27, 138-148 (1981).

46. S.K. Schaffer and J.M. Prausnitz, AIChE J. 27, 844-848 (1981).

47. P.L. Bolden, J.C. Hoskins and A.D. King, Jr., J. Colloid Interface Sci. 91, 454-463 (1983)

48. D.S. Abrams, F. Seneci, P.L. Chueh and J.M. Prausnitz, Ind. Eng. Chem. Fundam. 14, $52-54(1975)$.

49. H.C. Van Ness and M.M. Abbott, AIChE J. 25, 645-53 (1979).

50. J.P. 0'Conne11, Fluid Phase Equil. 6, 21-38 (1981).

51. P.M. Mathias and J.P. O'Conne11, Chem. Eng. Sci. 36, 1123-1132 (1981).

52. V. Brandani and J.M. Prausnitz, Fluid Phase Equil. 7, 259-274 (1981).

53. Y.T. Shah, Gas-Liquid-Solid Reactions, McGraw-Hil1, New-York (1979).

54. O.F. Mixon, B. Gumowski and B.H. Carpenter, Ind. Eng. Chem. Fundam. 4, 455-459 (1965).

55. S.G. Sayegh and J.H. Vera, Chem. Eng. Sci. 35, 2247-2256 (1980).

56. G. Nocon, U. Weidlich, J. Gmehling and U. Onken, Ber. Bunsenges. Phys. Chem. 87, $17-23(1983)$

57. J.P. O'Connei1, AIChE J. 17, 658-663 (1971).

58. M. Yorizane and Y. Miyano, AIChE J. 24, 181-186 (1978).

59. R.G. Linford and D.G.T. Thornhil1, (a) J. Appl. Chem. Biotechnol. 28, 649-659 (1978); (b) J. Chem. Techn. Biotechnol. 30, 547-556 (1980).

60. J.K. Kung, F.N. Nazario, J. Joffe and D. Tassios, Ind. Eng. Chem. Process Des. Dev. 23, $170-175$ (1984).

61. H.C. Van Ness, Ind. Eng. Chem. Fundam. 18, 431-433 (1979).

62. Y.P. Handa and G.C. Benson, Fluid Phase Equil. 8, 161-180 (1982).

63. J.H. Dymond and E.B. Smith, The Virial Coefficients of Pure Gases and Liquids. A Critical Compilation, Clarendon Press, Oxford (1980).

64. R.W. Potter II and M.A. Clynne, J. Solution Chem. 7, 837-844 (1978).

65. R. Crovetto, R. Fernández-Prini and M.L. Japas, J. Chem. Phys. 76, 1077-1086 (1982).

66. P.L. Chueh, N.K. Muirbrook and J.M. Prausnitz, AIChE J. 11, 1097-1102 (1965).

67. I.R. Krichevsky and J.S. Kasarnovsky, J. Am. Chem. Soc. 57, 2168-2171 (1935).

68. W.J. Parkinson and N. de Nevers, Ind. Eng. Chem. Fundam. 8, 709-713 (1969).

69. R.E. Gibbs and H.C. Van Ness, Ind. Eng. Chem. Fundam. 10, 312-315 (1971).

70. J.C. Moore, R. Battino, T.R. Rettich, Y.P. Handa and E. Wilhelm, J. Chem. Eng. Data 27 , $22-24(1982)$

71. Y.P. Handa, P.J. D'Arcy and G.C. Benson, Fluid Phase Equil. 8, 181-196 (1982).

72. I.R. Krichersky and A.A. Il inskaya, Acta Physicochim. URSS 20, 327-348 (1945).

73. E. Bender, U. Klein, W.Ph. Schmitt and J.M. Prausnitz, Fluid Phase Equil. 15, $24\{-255(1984)$.

74. E. Wilhe1m (a) J. Chem. Phys. 63, 3379-3381 (1975); (b) Proc. 4th Int. Conf. Chem. Thermodyn., Montpell ier (France), 26 to 30 August 1975, vol.2, pp. 87-94.

75. E. Withe1m, R. Schano, G. Becker, G.H. Findenegg and F. Kohler, Trans. Faraday Soc. 65, 1443-1455 (1969).

76. P.L. Chueh and J.M. Prausnitz, AIChE J. 13, 896-902 (1967).

77. R. De Santis and B. Grande, AIChE J. 25, 931-938 (1979).

78. H. Orbey and J.H. Vera, AIChE J. 29, 107-113 (1983).

79. R. Battino and H.L. Clever, Chem. Rev. 66, 395-463 (1966).

80. B.B. Benson and D. Krause, J. Chem. Phys. 64, 689-709 (1976).

81. B.B. Benson, D. Krause and M.A. Peterson, J. Solution Chem. 8, 655-690 (1979).

82. (a) M.W. Cook and D.N. Hanson, Rev. Sci. Instr. 28, 370-374 (1957).

(b) M.W. Cook, D.N. Hanson and B.J. Alder, J. Chem. Phys. 26, 748-751 (1957).

83. T.R. Rettich, Y.P. Handa, R. Battino and E. Wilhelm, J. Phys. Chem. $85,3230-3237$ (1981).

84. T.R. Rettich, R. Battino and E. Wilhe1m, Ber. Bunsenges. Phys. Chem. 86, 1128-1132

85. T.R. Rettich, R. Battino and E. Wilhelm, J. Solution Chem. 13, 335 (1984). 
86. R. Battino, M. Banzhof, M. Bogan and E. Wilhe1m, Anal. Chem. 43, 806-807 ( 1971 ).

87. R. Jaeckel in Handbuch der Physik, Bd. 12, S. Flügge, editor, pp. 515-608. Springer-Verlag, Berl in (1958).

88. J.G. Hayden and J.P. O'Conne11, Ind. Eng. Chem., Process Des. Develop. 14, 209-2१6 ( १975).

89. K.S. Pitzer and R.F. Cur1, Jr., J. Am. Chem. Soc. 79, 2369-2370 (1957).

90. C. Tsonopoutos, Adv. Chem. Ser. 182, 143-162 (1979).

91. D.R. Pesuit, (a) J. Chem. Phys. 67, 5341-5351 (1977); (b) Ind. Eng. Chem. Fundam. 17, 235-242 ( $\uparrow 978$ ).

92. F. Kohler, J. Fischer and E. Wilhelm, J. Mol. Struct. 84, 245-250 (1982).

93. R. De Santis, G.J.F. Breedveld and J.M. Prausnitz, Ind. Eng. Chem. Process Des. Dev. 13, 374-377 ( 1974$)$.

94. R. Nakamura, G.J.F. Breedveld and J.M. Prausnitz, Ind. Eng. Chem. Process Des. Dev. 15, $557-564(1976)$.

95. N.F. Carnahan and K.E. Starling, AIChE J. 18, 1184-1189 (1972).

96. S.W. Bre1vi and J.P. O'Connel1, AIChE J. 18, 1239-1243 (1972).

97. R.A. Pierotti, (a) J. Phys. Chem. 67, 1840-1845 (1963); (b) J. Phys. Chem. 69, 281-288 (1965).

98. H. Reiss, Adv. Chem. Phys. 9, 1-84 (1965).

99. E. Wilhelm and R. Battino, J. Chem. Thermodyn. 3, 379-392 (1971).

100. E. Wilhelm and R. Battino, (a) J. Chem. Phys. 55, 4012-4017 (1971); (b) J. Chem. Phys. 56, 563-566 (1972).

101. E.C.W. Clarke and D.N. Glew, Trans. Faraday Soc. 62, 539-547 (1966).

102. E. Withe1m (a) J. Chem. Phys. 58, 3558-3560 (1973); (b) Monatsh. Chem. 105, 291-301 (1974); (c) J. Chem. Phys. 60, 3896-3900 (1974).

103. G. Schuize and J.M. Prausnitz, Ind. Eng. Chem. Fundam. 20, 175-177 (1981).

T04. R. Battino and K.N. Marsh, Aust. J. Chem. 33, 1997-2003 (1980).

105. S.J. Gi11 and I. Wadsö, J. Chem. Thermodyn. 14, 905-919 (1982).

106. B.I. Lee and M.G. Kesler, AIChE J. 21, 510-527 (1975).

107. D.W. Scott and A.G. Osborn, J. Phys. Chem. 83, 2714-2723 (1979).

108. R. Battino, Fluid Phase Equil. 15, 231-240 (1984).

109. D. Beutier and H. Renon, AIChE J. 24, 1122-1125 (1978).

110. W. Hayduk and H. Laudie, AIChE J. 19, 1233-1238 (1973).

111. T. Rettich, R. Battino and E. Wilhelm, in preparation.

112. R. Bunsen, Ann. Chem. Pharm. 93, 1-50 (1855).

113. L.W. Winkler, Ber. Dtsch. Chem. Ges. 24, 89-101 (1891).

1१4. F. Kohler, E. Wilhelm and H. Posch, Adv. Mol. Relaxation Processes 8 , 195-239 (1976).

115. J.A. Barker and D. Henderson, Rev. Mod. Phys. 48, 587-671 (1976).

116. Y. Marcus, Introduction to Liquid State Chemistry, Wiley, London (1977).

1T7. T. Boub1ik, I. Nezbeda and K. Hlavaty, Statistical Thermodynamics of Simple Liquids and their Mixtures, Elsevier, Amsterdam (1980).

118. J.S. Rowl inson and F.L. Swinton, Liquids and Liquid Mixtures, 3rd edition, Butterworths, London (1982). 